\title{
PHASE ANALYSIS AND DENSIFICATION OF STEATITE-BASED CERAMICS
}

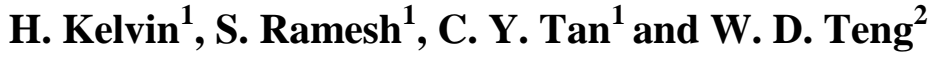 \\ ${ }^{1}$ Ceramics Technology Laboratory, University Tenaga Nasional \\ 43009 Kajang, Selangor, Malaysia \\ Email: ramesh@uniten.edu.my \\ ${ }^{2}$ Ceramics Technology Group, SIRIM Berhad, \\ 40911 Shah Alam, Selangor, Malaysia
}

\begin{abstract}
The effect of manganese oxide on the sintering of steatite-based ceramic was studied. Steatite powder used in this work was doped with varying amounts of manganese oxide- $5 \%$ to $30 \%(\mathrm{wt})$. The green samples were cold-isostatically pressed and pressureless sintered at temperatures ranging from $950^{\circ} \mathrm{C}$ to $1150^{\circ} \mathrm{C}$ using varying holding times. X-ray diffraction analysis revealed no secondary phases detected in any samples regardless of dopant addition and sintering conditions. It was revealed that the bulk density of steatite ceramic increased with manganese oxide when sintering at $1050^{\circ} \mathrm{C}$. However, sintering at $1100^{\circ} \mathrm{C}$ using 1 minute holding time was found to be the most effective in enhancing the bulk density as well as the Vickers hardness of manganese oxide-doped steatite ceramic.
\end{abstract}

Keywords: Manganese oxide, steatite, bulk density, Young's modulus, hardness.

\section{INTRODUCTION}

Almost every product is designed for a functionality towards some specific purposes. However, the functionality of products always depends strongly on the material used to fabricate them. In an effort to enhance the reliability of materials, a vast amount of investment has been devoted to the development of advanced materials. In particular, the processing of advanced ceramics is always more challenging than that of metals and polymers due to their inherent brittleness. A high melting temperature is another drawback in the processing of advanced ceramics. However, it is the high melting temperature which makes ceramic one of the most attractive structural and insulating materials used in the refractory industry. Historically, most of the oxides that were used in refractory applications were traditional ceramics prepared from clays or other readily available mineral-based raw materials (Smith and Fahrenholtz, 2008). The major categories of traditional refractories are fire clay, high alumina and silica (Kingery et al., 1976). They are widely used as refractory materials because of their capability for high temperature operation without any hazardous degradation in chemical, mechanical or electrical properties. However, a balance between properties and material cost has always been a concern of most manufacturers. Therefore, steatite-based ceramics (SBC) are being considered as a potential replacement for traditional fire clay and high alumina as a cost-effective way to meet performance requirements.

SBC are not only desirable for use in thermal insulations, but also in electronics and electrical applications owing to their low dielectric losses, high temperature 
resistance and high mechanical strength (Kharitonov and Shapiro, 1989). They are easier to form and fire at lower temperatures when compared to alumina, making them more economical to produce (Soykan, 2007). The phase structure of steatite is predominantly composed of magnesium silicate $\left(\mathrm{MgSiO}_{3}\right)$. It is one of the meta-silicates that form the main components of the $\mathrm{MgO}-\mathrm{Al}_{2} \mathrm{O}_{3}-\mathrm{SiO}_{2}$ system (Rohan et al., 2004). The three commonly observed polymorphs at ambient pressure are low-clinoenstatite, ortho-enstatite and protoenstatite (Sarver and Hummel, 1962; Bloor, 1964; Lee and Heuer, 1987; Mielcarek et al., 2004). For industrial use, SBC usually is in the form of the enstatite phase, whose density is $3.21 \mathrm{~g} / \mathrm{cc}$ and melting point is $1557^{\circ} \mathrm{C}$ (Chao, 1994). Some studies have shown that densification could be improved by doping steatite with boron oxide, aluminum oxide, antimony oxide or by substituting magnesium ions (Tripathi et al., 1978; Kulkarni et al., 1990; Soykan, 2007). In all these studies, stabilization of the protoenstatite phase was achieved but frequently resulted in grain coarsening and low mechanical strength. In addition, various mechanisms have been proposed to explain the degradation in strength but a universal consensus on the actual mechanism has yet to be achieved. The aim of the present work was to formulate a steatite-based ceramic composition using local indigenous materials with manganese oxide $\left(\mathrm{MnO}_{2}\right)$ as sintering additives.

\section{MATERIALS AND METHODS}

The steatite and dopant used in this work were commercially available powders. A series of powders were prepared and the amount of dopant used was 5, 10, 20 and 30 wt $\%$. In a typical process, the powders were mixed and ball milled for 1 hour. After the mixing, the slurry was dried, crushed and sieved into powder form. The obtained powders were then uniaxially pressed at $2.5-3.0 \mathrm{MPa}$ into circular discs $(20 \mathrm{~mm}$ diameter) and rectangular bars $(4 \times 13 \times 32 \mathrm{~mm})$ and subsequently cold isostatically pressed at $200 \mathrm{MPa}$ (Riken Seiki, Japan). The compacted green samples were subsequently sintered at temperatures ranging from $950^{\circ} \mathrm{C}$ to $1100^{\circ} \mathrm{C}$, with ramp rate of $10^{\circ} \mathrm{C} / \mathrm{min}$ using three different soaking times i.e. $30 \mathrm{~min} ., 60 \mathrm{~min}$. and $120 \mathrm{~min}$. Another set of samples were sintered at $1100^{\circ} \mathrm{C}$ with a soaking time of $1 \mathrm{~min}$. for comparison study. The phase stability studies for two selected sets of sintered samples were carried out by using an X-ray diffractometer (Geirger-Flex, Rigaku Japan). The bulk densities of these compacts were measured by the water immersion technique (Mettler Toledo, Switzerland) and Young's Modulus was calculated using the resonant frequency method via a commercial testing instrument (GrindoSonoc: MK5 'Industrial', Belgium). The hardness of the sintered samples was tested using a Vickers hardness tester.

\section{RESULTS AND DISCUSSION}

The sinterability of the SBC samples was compared in terms of phase stability, bulk density, Young's modulus and hardness. The XRD phase analysis as shown in Figure 1 and Figure 2 indicate that all the SBC samples were composed predominantly of $\mathrm{MgSiO}_{3}$ with no decomposition into secondary phase such as $\mathrm{Mg}_{2} \mathrm{SiO}_{4}$ or forsterite. Figure 1 indicates that magnesium silicate is the major phase detected for SBC samples sintered at $950^{\circ} \mathrm{C} / 120 \mathrm{~min}$. with the addition of less than $10 \mathrm{wt} \%$ of $\mathrm{MnO}_{2}$. The presence of clinoenstatite was observed in samples doped with $20 \mathrm{wt} \%$ of $\mathrm{MnO}_{2}$ and above. As pointed out by Soykan (2007), there are three well-defined phases that could exist in $\mathrm{MgSiO}_{3}$, i.e. orthoenstatite, prothoenstatite, and clinoenstatite. Complete 
transformation from protoenstatite to clinoenstatite would require rapid cooling from $1200^{\circ} \mathrm{C}$ or above down to room temperature (Lee and Heuer, 1987; Siyu et al., 2007). However, in the present work it was revealed that the increase of the amount of $\mathrm{MnO}_{2}$ addition seems to have a positive effect in aiding the prothoenstatite phase transformation as shown in Figure 2.

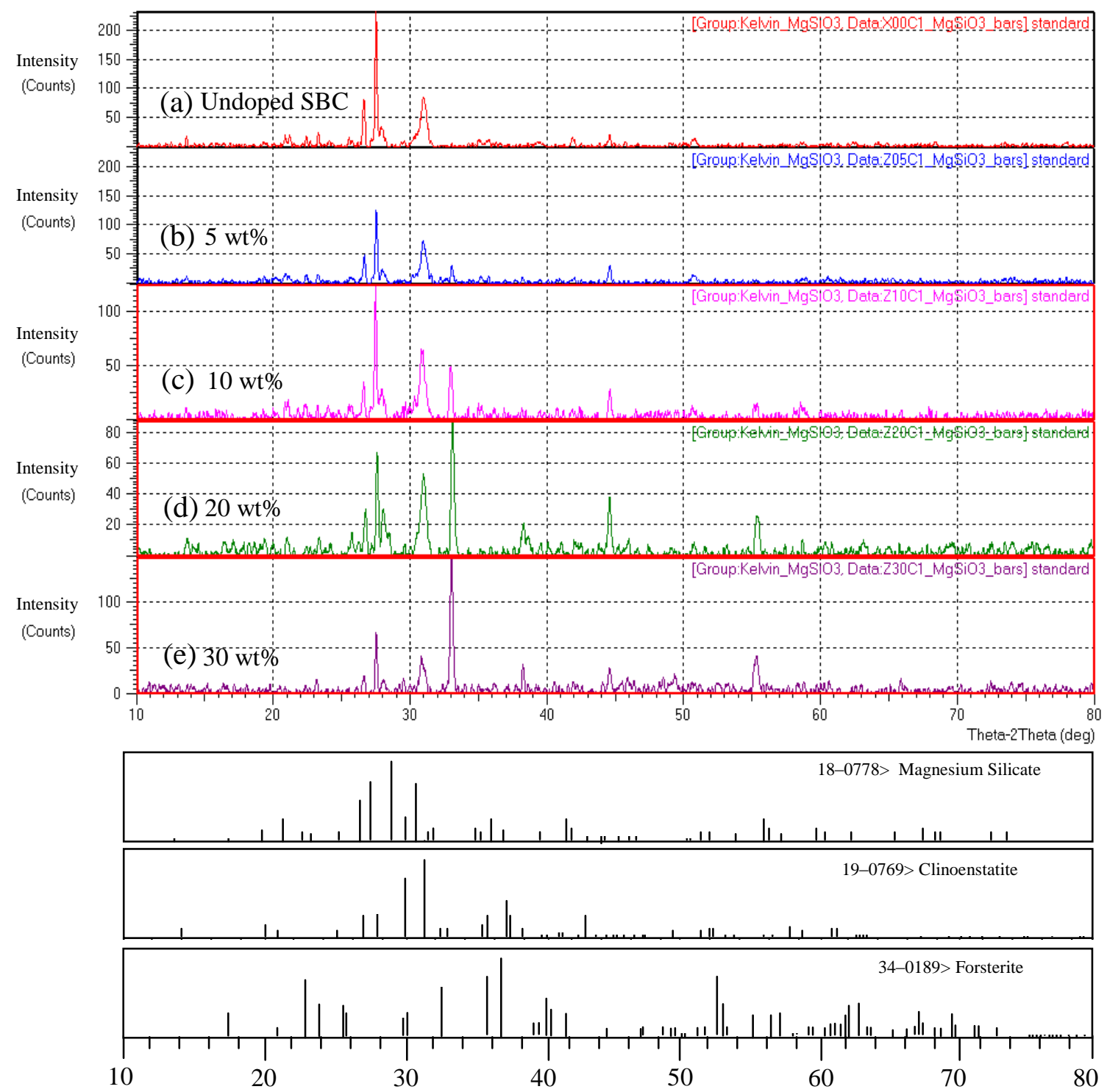

Figure 1. XRD patterns of SBC samples sintered at $950^{\circ} \mathrm{C}$ using 120 minutes soaking time

The XRD patterns shown in Figure 2 revealed that all the doped samples were composed of clinoenstatite phase at room temperature after sintering at $1100^{\circ} \mathrm{C}$ with 1 min. soaking time rather than rapid cooling of protoenstatite phase from $1200^{\circ} \mathrm{C}$ or higher to room temperature. According to Smyth (1974) the proto- to clino- and clinoto proto- inversions displayed the characteristics of martensitic transformations i.e. diffusionless, athermal and display a well-defined orientation relationship. This martensitic type of transformation is normally accompanied by volume change that 
could lead to material cracking and this has been the main concern with the use of steatite-based ceramics in industry (Peicang and Xiayoun, 1988; Vereshchagin and Gurina, 1997; Vela et al., 2007; Reynard et al., 2008). Therefore, the result obtained in this work is encouraging since there was no cracking found in the doped samples after sintering.
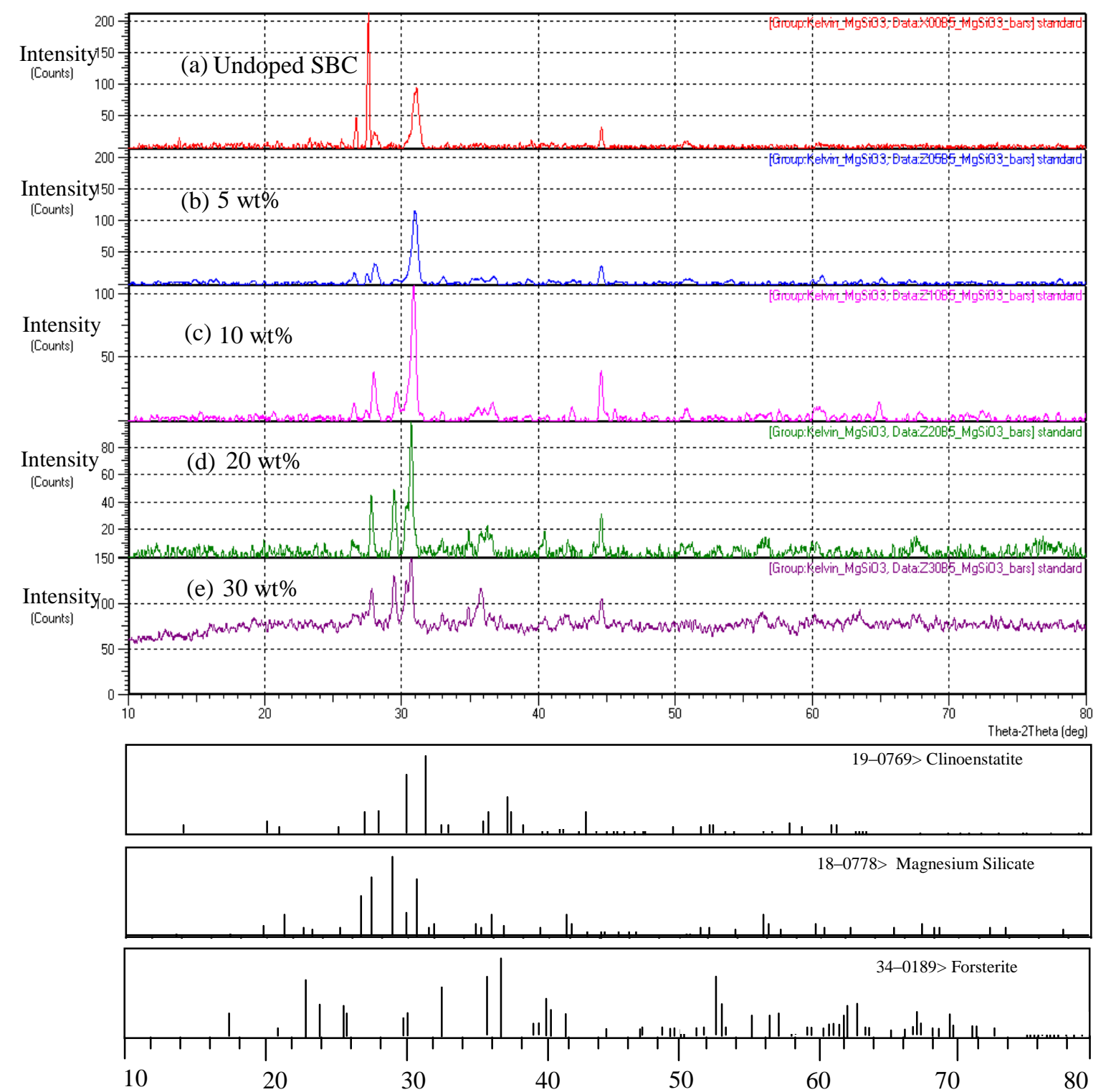

Figure 2. XRD patterns of SBC samples sintered at $1100^{\circ} \mathrm{C}$ using 1 minute soaking time

The effect of holding time as a function of dopant content on the densification of steatite sintered at $950^{\circ} \mathrm{C}$ is shown in Figure 3. A similar density trend was observed for samples sintered at $1000^{\circ} \mathrm{C}$. The results indicated that regardless of holding time, the dopant was not effective in aiding sintering of steatite when sintered below $1000^{\circ} \mathrm{C}$. However, as the sintering temperature was increased to $1050^{\circ} \mathrm{C}$, this was accompanied by an increased in the bulk density with dopant content as shown in Figure 4. The beneficial effect of manganese oxide in aiding the densification of steatite has been revealed. In general, regardless of holding time, it was found that SBC samples doped 
with $20 \mathrm{wt} \%$ exhibited the highest density, greater than $2.35 \mathrm{Mgm}^{-3}$ with maximum value of $2.45 \mathrm{Mgm}^{-3}$ being measured for the 120 minutes soaking time sample. These results are considered excellent since a similar densification could only be achieved for steatite ceramics when doped with boron oxide and sintered above $1100^{\circ} \mathrm{C}$ (Soykan, 2007) or doped with barium carbonate and sintered above $1240^{\circ} \mathrm{C}$ (Vela et al., 2007).

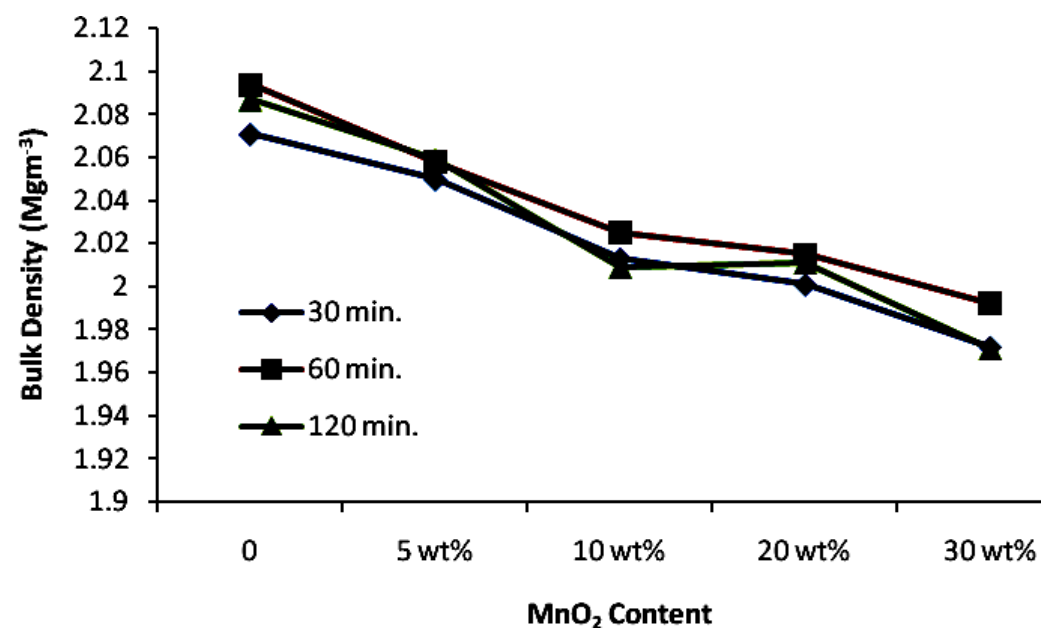

Figure 3. Bulk density as a function of dopant content for samples sintered at $950^{\circ} \mathrm{C}$ using different holding times.

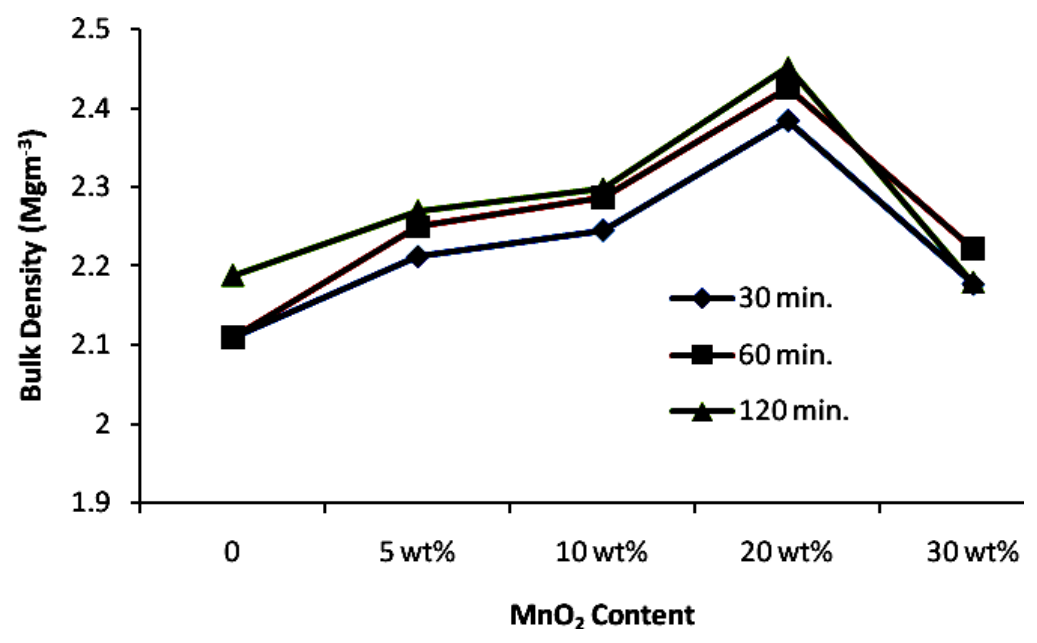

Figure 4. Bulk density as a function of dopant content for samples sintered at $1050^{\circ} \mathrm{C}$ using different holding time.

The effect of manganese addition on the Young's modulus of steatite sintered at $1050^{\circ} \mathrm{C}$ is shown in Figure 5. In general, regardless of dopant content and holding time, the Young's modulus trend is in agreement with the bulk density trend as shown in Figure 4. The study found that the bulk density of ceramic governs the stiffness of the sintered body. Attempts to sinter the ceramic above $1050^{\circ} \mathrm{C}$ using $30 \mathrm{~min}$. soaking time or above were detrimental since the samples showed signs of bloating and melting. An attempt was made to sinter the ceramic at $1100^{\circ} \mathrm{C}$ using a very short holding time of 1 minute. The result was encouraging. There was no sign of melting and the samples were found to be intact after sintering. The bulk density and Vickers hardness variation of the 
sintered samples as a function of dopant content when sintered at $1100^{\circ} \mathrm{C}$ using $1 \mathrm{~min}$. holding time are shown in Figure 6. The results show that the hardness increased linearly with increasing dopant content and attained a maximum of $4 \mathrm{GPa}$ at $20 \mathrm{wt} \%$ $\mathrm{MnO}_{2}$ addition. This value is an increased of threefold when compared to the undoped steatite ceramic. This improvement in hardness was associated with an increased in density resulting from the addition of manganese oxide. From the results obtained, it is envisaged that liquid phase sintering is the probable mechanism governing the densification of $\mathrm{MnO}_{2}$-doped steatite ceramic and this is in agreement with the observation made by Vela et al. (2007).

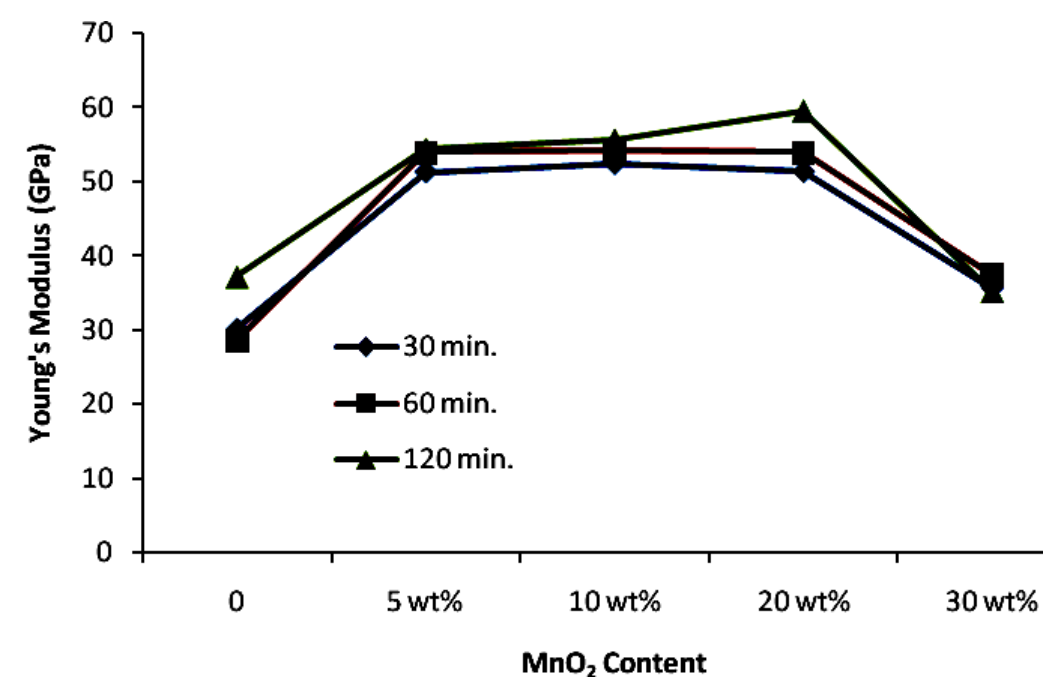

Figure 5. The effect of dopant on the Young's modulus of steatite sintered at $1050^{\circ} \mathrm{C}$ using various holding time.

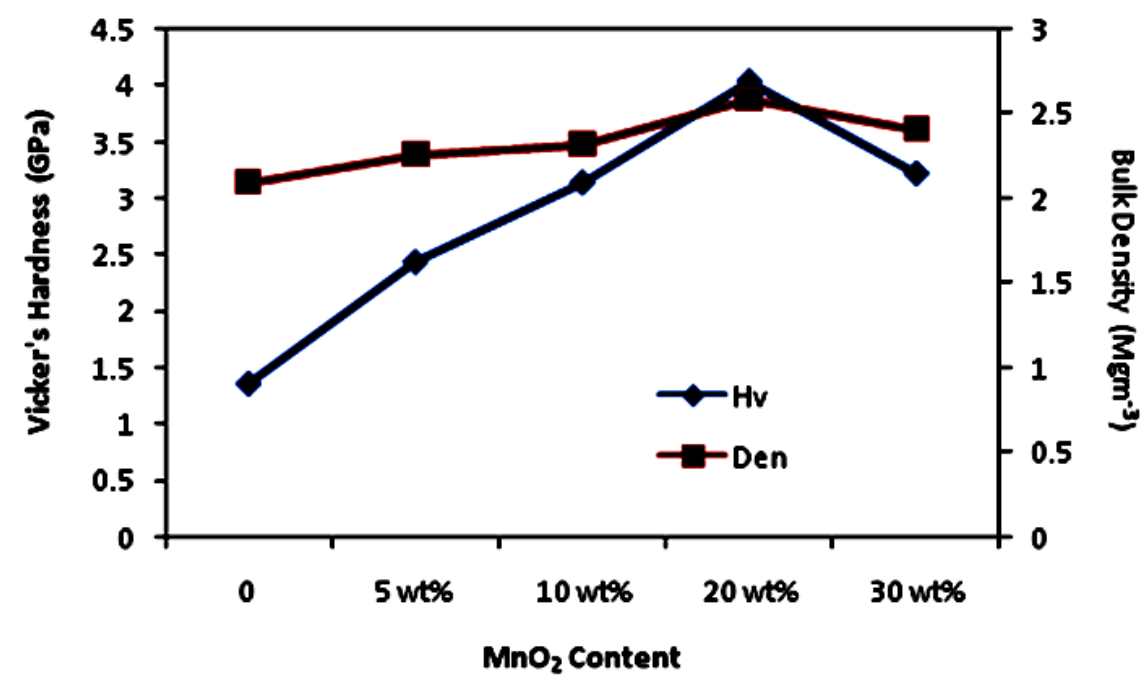

Figure 6. Effect of dopant content on bulk density and Vickers hardness of stetatite samples doped with varying amount of manganese oxide sintered at $1100^{\circ} \mathrm{C} / 1 \mathrm{~min}$ holding time. 


\section{CONCLUSIONS}

In the present work the effects of holding time and manganese oxide on the sintering of steatite-based ceramics were studied. The beneficial effect of manganese oxide in aiding the densification of steatite has been revealed, particularly when sintered at $1050^{\circ} \mathrm{C}$ and $1100^{\circ} \mathrm{C}$ using 1 minute holding time. It was found that steatite doped with $20 \mathrm{wt} \%$ manganese oxide exhibited the highest density of $>2.35 \mathrm{Mgm}^{-3}$, with maximum value of $2.45 \mathrm{Mgm}^{-3}$ measured for the samples with 120 minutes soaking time. A maximum hardness of up to $4 \mathrm{GPa}$ was measured for the $20 \mathrm{wt} \% \mathrm{MnO}_{2}$-doped steatite when sintered at $1100^{\circ} \mathrm{C}$ using 1 minute of holding time. This improvement in hardness was associated with an increase in density resulting from the addition of manganese oxide.

\section{ACKNOWLEDGEMENTS}

This work was supported by the Ministry of Science Technology and Innovation of Malaysia under NSF scheme (M/0035/01/2009/IND). The authors gratefully acknowledge the support provided by UNITEN and SIRIM Berhad.

\section{REFERENCES}

Bloor, E.C. (1964) Conversion in steatite ceramics. Journal of British Ceramic Society, 63: 309-316.

Chao, M.H. (1994) Phase stability of chemically derived enstatite $\left(\mathrm{MgSiO}_{3}\right)$ powders. Journal of the American Ceramic Society, 77: 2625-2631.

Kharitonov, F.Y. and Shapiro, L.E. (1989) A steatite material having a wide sintering range. Glass and Ceramics, 46: 162-165.

Kingery, W.D., Bowen, H.K. and Uhlmann, D.R. (1976) Introduction to Ceramics. New York: Wiley.

Kulkarni, A.K., Dalvi, P.Y. and Barde, M.L. (1990) Evaluation of steatite based machinable ceramic insulator for UHV systems. Transactions of Powder Metallurgy Association of India, 17: 101-109.

Lee, W.E. and Heuer, A.H. (1987) On the polymorphism of enstatite. Journal of the American Ceramic Society, 70: 349-360.

Mielcarek, W., Dorota, N.W. and Krystyna, P. (2004) Correlation between $\mathrm{MgSiO}_{3}$ phases and mechanical durability of steatite ceramics. Journal of the European Ceramic Society, 24: 3817-3821.

Peicang, X. and Xiayoun, Z. (1988) Mineral physical characteristics of pyroxene phase transformation and a probe into the mechanism of talc porcelain aging. Acta Mineral. Sin., 8: 104-112.

Reynard, B., Bass, J.D. and Jackson, J.M. (2008) Rapid identification of steatite-enstatite polymorphs at various temperatures. Journal of the European Ceramic Society, 28: 2459-2462.

Rohan, P., Neufuss, K., Matějíček, J., Dubskỳ, J., Prchlík, L. and Holzgartner, C. (2004) Thermal and mechanical properties of cordierite, mullite and steatite produced by plasma spraying. Ceramics International, 30: 597-603.

Sarver, J.F. and Hummel, F.A. (1962) Stability relations of magnesium metasilicate polymorphs. Journal of the American Ceramic Society, 55: 152-156.

Siyu, N., Lee, C. and Jiang, C. (2007) Preparation and characterization of forsterite $\left(\mathrm{Mg}_{2} \mathrm{SiO}_{4}\right)$ bioceramics. Ceramics International, 33: 83-88. 
Smith, J.D. and Fahrenholtz, W.G. (2008) Refractory Oxides. Ceramics and glass materials: Structure, Properties and Processing. Shackelford, J.F. and Doremus, R.H. (eds.). New York: Springer, 87-110.

Soykan, H.Ş. (2007) Low-temperature fabrication of steatite ceramics with boron oxide addition. Ceramics International, 33: 911-914.

Tripathi, U.C., Agrawal, G.N. and Joshi, V.C. (1978) Transactions of India Ceramic Society, 37(5): 179-182.

Vela, E., Peiteado, M., García, F., Caballero, A.C. and Fernández, J.F. (2007) Sintering behavior of steatite materials with barium carbonate flux. Ceramics International, 33: $1325-1329$.

Vereshchagin, V.I. and Gurina, V.N. (1997) Polymorphism of magnesium metasilicate and its role in the production of no aging steatite ceramics. Glass and Ceramics, 54: 365367. 